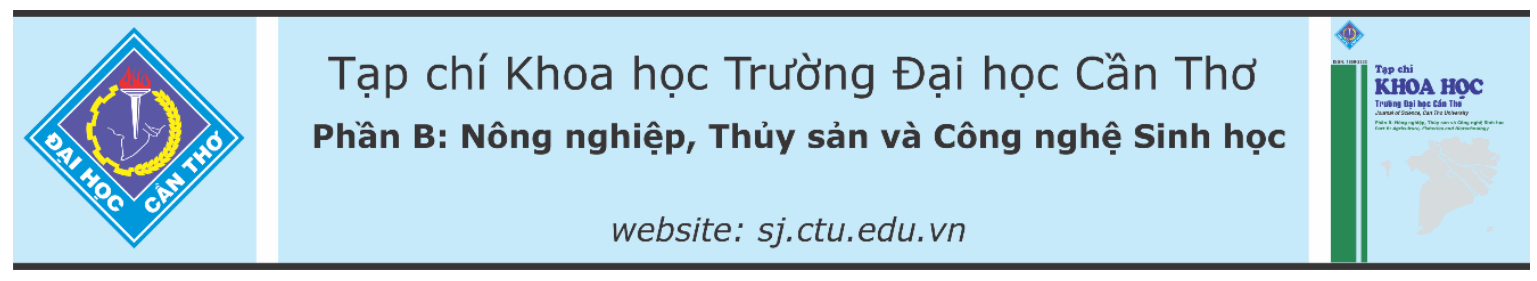

DOI:10.22144/ctu.jvn.2021.155

\title{
ĐÁNH GIÁ KHẢ NĂNG CUNG CẤP DƯÕ̃NG CHẤT CỦA ĐẤT PHÙ SA TRONG ĐÊ, HẤP THU NPK VÀ ĐÁP ÚNG NĂNG SUẤT MÈ ĐEN (Sesamum indicum L.)
}

Nguyễn Quốc Khương ${ }^{1}$, Lý Ngọc Thanh Xuân ${ }^{2}$, Trần Ngọc Hữu ${ }^{1}$, Nguyễn Hồng Huế ${ }^{1}$, Nguyễn Minh Phụng ${ }^{1}$, Cao Tiến Giang ${ }^{1}$ và Lê Vĩnh Thúc ${ }^{1 *}$

${ }^{1}$ Bộ môn Khoa học cây trồng, Khoa Nông nghiệp, Truờng Đại học Cần Tho'

${ }^{2}$ Khu Thí nghiệm - Thục hành, Phòng Quản trị - Thiết bị, Truờng Đại học An Giang, Đại học Quốc gia thành phố Hồ Chí Minh

*Người chịu trách nhiệm về bài viết: Lê Vĩnh Thúc (email: lvthuc@ctu.edu.vn)

\section{Thông tin chung:}

Ngày nhận bài: $27 / 10 / 2020$

Ngày nhận bài sưa: 23/12/2020

Ngày duyệt đăng: 29/10/2021

\section{Title:}

Evaluation of indigenous nutrition supply capability from alluvial soil in dyke, NPK uptake, and sesame (Sesamum indicum L.) yield response

\section{Tù khóa:}

Dinh duõng khoáng $N, P, K$, mè đen, đất phù sa không bồi, kỹ thuật lô khuyết

\section{Keywords:}

Alluvial soil in dyke, mineral nutrition of $N, P, K$, omission technique, sesame

\begin{abstract}
This study was to (i) determine the effects of NPK application on growth, yield and NPK uptake of sesame and (ii) estimate the indigenous NPK supplying capabilities of soil. The experiment was a randomized complete block design on alluvial soils, with four replications. The treatments included (i) fully fertilization (NPK); (ii) potassium omission (NP); (ii) phosphorus omission (NK); (iv) nitrogen omission (PK). Results showed that sesame yield response was recorded $34.38,3.93$ and $1.35 \mathrm{~g} \mathrm{~m}^{-2}$ for $\mathrm{N}$, $\mathrm{P}_{2} \mathrm{O}_{5}$ and $\mathrm{K}_{2} \mathrm{O}$ fertilizers, respectively. The nitrogen fertilizer application significantly increased sesame yield through improving the number of capsules per plant. Moreover, the phosphorus or potassium application enhanced sesame height and the number of capsules, but they have not been increased yield. N, P and K uptake in NPK treatment was 4.43, 2.05 and $5.75 \mathrm{~g} \mathrm{~m}^{-2}$, respectively. The indigenous soil $N, P, K$ supplying capability was $2.31 \mathrm{~g} \mathrm{~m}^{-2}$ for $N, 4.99 \mathrm{~g} \mathrm{~m}^{-2}$ for $P$ and $1.69 \mathrm{~g} \mathrm{~m}^{-2}$ for $K$ in sesame.
\end{abstract}

\section{TÓM TẮT}

Nghiên cứu được thưc hiện nhằm muc tiêu: (i) xác định ảnh hưởng của bón khuyết NPK lên sinh trưởng, năng suất và hấp thu dinh duỡng NPK trong cây mè; (ii) đánh giá khả năng cung cấp duõ̃ng chất bản địa của đất. Thi nghiệm bố trí theo khối hoàn toàn ngấu nhiên gồm 4 nghiệm thức (i) bón đầy đủ $N, P, K$, (ii) Bón khuyết kali, (iii) bón khuyết lân, (iv) bón khuyết đạm, với 4 lặp lại. Kết quả nghiên cứu cho thấy đáp ứng năng suất của bón $\mathrm{N}, \mathrm{P}_{2} \mathrm{O}_{5}$ và $\mathrm{K}_{2} \mathrm{O}$ được xác định là $34,38,3,93$ và $1,35 \mathrm{~g} \mathrm{~m}^{-2}$. Bón đạm giúp tăng năng suất hạt mè thông qua tăng số trái trên cây. Ngoài ra, bón lân hoạc kali chỉ tăng chiều cao cây và số trái, nhung chưa tăng năng suất mè. Luợng hấp thu $N, P$ và K ở nghiệm thức bón đầy đủ NPK lần lượt là 4,43, 2,05 và $5,75 \mathrm{~g} \mathrm{~m}^{-2}$. Tổng lượng $\mathrm{N}, P$ và $K$ đất phù sa có khả năng cung cấp là $2,31,1,28$ và $3,96 \mathrm{~g} \mathrm{~m}^{-2}$.

\section{MỞ ĐẦU}

Phân bón là một trong những yếu tố quan trọng ảnh hưởng đến sự sinh trưởng và tăng năng suất của cây mè. Việc sử dụng các loại phân hóa học là cần thiết để cung cấp các dưỡng chất cho cây mè đạt năng suất cao. Trong đó, đạm giúp tăng sinh trưởng, 
năng suất và phẩm chất hạt (Zenawi et al., 2019). Khi kết hợp bổ sung giữa phân lân và đạm sẽ tăng cường sự phát triển của bộ rễ, giúp cung cấp các chất dinh dưỡng và tăng khả năng tích lũy chất khô (Ali et al., 2010; Amare et al., 2019). Bên cạnh đó, kali là một trong những dinh dưỡng đa lượng thiết yếu cho cây trồng tăng sinh trưởng (Bijarnia et al., 2019). Hơn nữa, việc chuyển đổi cơ cấu cây trồng ở một số địa phương, nên diện tích trồng mè ở Đồng bằng sông Cửu Long tăng lên (Nguyễn Văn Chương \& Võ Văn Quang, 2019). Trong đó, tỉnh Đồng Tháp có diện tích trồng mè lớn nhất với 4.951 ha và tiếp đến là Cần Thơ với diện tích trồng 2.000 ha (Trung tâm Tin học và Thống kê, 2019). Tuy nhiên, đến nay vẫn chưa có công thức phân khuyến cáo cho cây mè trong từng địa điểm kể trên. Vì vậy, đề tài được thực hiện nhằm mục tiêu: (i) xác định ảnh hưởng của bón khuyết NPK lên sinh trưởng, năng suất và hấp thu dinh dưỡng NPK của cây mè; (ii) định lượng khả năng cung cấp dưỡng chất bản địa của đất phù sa không bồi.

\section{VẬT LIỆU VÀ PHƯƠNG PHÁP}

\subsection{Vật liệu}

Thí nghiệm được thực hiện tại Trại Nghiên cứu và thực nghiệm Nông nghiệp, Trường Đại học Cần Thơ từ tháng 8 đến tháng 10 năm 2019. Các đặc tính đất thí nghiệm được trình bày ở Bảng 1 .

Bảng 1. Đặc tính hóa, lý của đất thí nghiệm ở độ sâu 0-20 cm tại Trại Nghiên cứu và thực nghiệm Nông nghiệp, Trường Đại học Cần Thơ, tháng 10/2019

\begin{tabular}{|c|c|c|c|c|c|c|c|}
\hline \multirow{2}{*}{$\begin{array}{c}\text { Độ sâu } \\
\text { (cm) }\end{array}$} & \multirow{2}{*}{ рНн2о } & \multirow{2}{*}{$\begin{array}{c}\text { Nhữu dụng } \\
\left(\mathbf{m g ~ N H}{ }^{+} \mathbf{k g}^{-1}\right)\end{array}$} & \multirow{2}{*}{$\begin{array}{c}\mathbf{P}_{\mathrm{dễ} \mathrm{tiêu}} \\
\left(\mathbf{m g ~ P ~} \mathbf{k g}^{-1}\right)\end{array}$} & \multirow{2}{*}{ 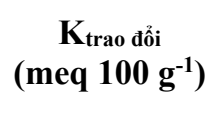 } & \multicolumn{3}{|c|}{ Sa cấu (\%) } \\
\hline & & & & & Sét & Thịt & Cát \\
\hline $0-20$ & 6,24 & 1,37 & 45,3 & 0,41 & 58,8 & 39,8 & 1,40 \\
\hline
\end{tabular}

Giống mè: sử dụng giống $\mathrm{ADB} 1$, thời gian sinh trưởng 75 ngày, hàm lượng dầu $>40 \%$, chống chịu sâu ăn lá cấp 1 .

Phân bón được sử dụng gồm urê $(46 \% \mathrm{~N})$, super lân $\left(16 \% \mathrm{P}_{2} \mathrm{O}_{5}, 20 \% \mathrm{CaO}\right)$, kali clorua $\left(60 \% \mathrm{~K}_{2} \mathrm{O}\right)$.

\subsection{Phương pháp}

Thí nghiệm được bố trí khối hoàn toàn ngẫu nhiên bao gồm 4 nghiệm thức, được trình bày ở Bảng 2, với 4 lần lặp lại, mỗi nghiệm thức là $1 \mathrm{~m}^{2}$. Mật độ giống theo khuyến cáo là $2 \mathrm{~g} \mathrm{~m}^{-2}$, lượng giống trong thí nghiệm này được giảm $10 \%$.

Bảng 2. Các nghiệm thức thí nghiệm trồng mè đen tại Trại Nghiên cứu và thực nghiệm Nông nghiệp, Trường Đại học Cần Thơ, tháng $10 / 2019$

\begin{tabular}{|c|c|c|}
\hline STT & Nghiệm thức & Mô tả \\
\hline 1 & NPK & $\begin{array}{l}\text { Lô được bón đầy đủ (NPK): Phân đạm, lân và kali được bón với lượng cao để } \\
\text { đảm bảo rằng những dinh dưỡng này không làm giới hạn năng suất hạt, kết hợp } \\
\text { giảm } 10 \% \text { mật độ }\end{array}$ \\
\hline 2 & NP & $\begin{array}{l}\text { Lô khuyết kali }(0-K) \text { : Không bón phân kali, nhưng phân đạm và lân vẫn được } \\
\text { bón đủ để đảm bảo rằng những dinh dưỡng đa lượng ngoài kali không làm giới } \\
\text { hạn năng suất hạt, kết hợp giảm } 10 \% \text { mật độ. }\end{array}$ \\
\hline 3 & NK & $\begin{array}{l}\text { Lô khuyết lân (0-P): Không bón phân lân, nhưng phân đạm và kali vẫn được bón } \\
\text { đủ để đảm bảo rằng những dinh dưỡng đa lượng ngoài lân không làm giới hạn } \\
\text { năng suất hạt, kết hợp giảm } 10 \% \text { mật độ. }\end{array}$ \\
\hline 4 & PK & $\begin{array}{l}\text { Lô khuyết đạm }(0-\mathrm{N}) \text { : Không bón phân đạm, nhưng phân lân và kali vẫn được } \\
\text { bón đủ để đảm bảo rằng những dinh dưỡng đa lượng ngoài đạm không làm giới } \\
\text { hạn năng suất hạt, kết hợp giảm } 10 \% \text { mật độ. }\end{array}$ \\
\hline
\end{tabular}

Công thức phân NPK: $60 \mathrm{~N}-60 \mathrm{P}_{2} \mathrm{O}_{5}-30 \mathrm{~K}_{2} \mathrm{O}(\mathrm{kg}$ $\left.h^{-1}\right)$. Các thời điểm bón phân gồm: lần 1 bón lót toàn bộ phân lân trước khi trồng 2 ngày; lần 2 bón $30 \%$ đạm $+50 \%$ kali vào 10 ngày sau trồng (NST); lần 3 bón $30 \%$ đạm vào $20 \mathrm{NST}$; lần 4 bón $40 \%$ đạm $+50 \%$ kali vào $40 \mathrm{NST}$.
Phương pháp thu mẫu đất: Mẫu đất đầu vụ được lấy ở độ sâu $0-20 \mathrm{~cm}$. Lấy 5 điểm theo đường chéo góc, trộn đều để lấy một mẫu đại diện khoảng $500 \mathrm{~g}$ cho vào túi nhựa, ghi ký hiệu mẫu. Phơi khô mẫu trong không khí rồi nghiền nhỏ qua rây $2,0 \mathrm{~mm}$ và rây $0,5 \mathrm{~mm}$ để tiến hành phân tích mẫu. Vào thời điểm thu hoạch, mẫu đất được thu ở 3 vị trí để trộn đều thành 1 mẫu cho mỗi lô. 
Phương pháp thu và xử lý mẫu thực vật: Sinh khối lá, thân, vỏ và hạt của cây mè được thu trên diện tích $0,25 \mathrm{~m}^{2}$ vào giai đoạn chín sinh lý. Sau đó, sấy khô ở $70^{\circ} \mathrm{C}$ trong 72 giờ để xác định sinh khối khô và phân tích NPK.

Phương pháp xác định đặc tính đất: $\mathrm{pH}$ được trích tỉ lệ đất:nước $(1: 2,5)$, đo bằng $\mathrm{pH}$ kế; Đạm hữu dụng được xác định bằng phương pháp phenol blue ở bước sóng $640 \mathrm{~nm}$, dung dịch trích là $\mathrm{KCl} 2 \mathrm{M}$; Lân dễ tiêu được xác định bằng phương pháp trích đất với $0,1 \mathrm{~N} \mathrm{HCl}+0,03 \mathrm{~N} \mathrm{NH}_{4} \mathrm{~F}$, tỉ lệ đất:nước là $1: 7$, so màu với chất khử là ascorbic acid trên máy quang phổ kế ở bước sóng $880 \mathrm{~nm}$. Hàm lượng $\mathrm{K}^{+}$ được đo trên máy hấp thu nguyên tử từ dung dịch trích bằng $\mathrm{BaCl}_{2} 0,1 \mathrm{M}$ (Sparks et al., 1996). Sa cấu được xác định bằng phương pháp ống hút Robinson.

Phuoong pháp xác định các chỉ tiêu nông học: Tất cả các chỉ tiêu sinh trưởng được xác định trên 10 cây mè vào thời điểm thu hoạch, riêng chiều dài lá và độ rộng lá được xác định vào thời điểm kích thước tối đa.

Sinh truởng cây mè: Chiều cao cây $(\mathrm{cm})$ được đo chiều cao cây từ gốc đến đỉnh sinh trưởng cao nhất của cây. Chiều cao đóng trái đầu tiên được đo từ gốc đến vị trí đậu trái đầu tiên. Đường kính cây được đo đường kính gốc, đường kính thân và đường kính ngọn sau đó lấy trung bình. Đo chiều dài và rộng lá được đo chiều dài và rộng lá thứ 10 từ dưới đất trở lên khi lá thứ 10 phát triển hoàn toàn đến khi đạt kích thước tối đa.

Thành phần năng suất: Được xác định trên 10 cây mè vào thời điểm thu hoạch.

Số trái/cây: Đếm số trái trên cây. Đo kích thước trái: Đo chiều dài và đường kính trái. Khối lượng 1.000 hạt (g): Cân trọng lượng 1.000 hạt mè.

Năng suất hạt mè: Cân trọng lượng hạt trên 0.25 $\mathrm{m}^{2}$. Dựa vào ẩm độ tại thời điểm thu hoạch sau đó quy đổi sang ẩm độ $8 \%$

Sinh khối thân lá, vỏ và hạt: Cân sinh khối khô của $1 \mathrm{~m}^{2}$ trên mỗi lô.

Hấp thu dinh duỡng NPK: Tính hấp thu NPK dựa trên sinh khối khô của từng bộ phận (thân lá, vỏ và hạt) $\mathrm{x}$ hàm lượng của từng dưỡng chất $\mathrm{N}, \mathrm{P}, \mathrm{K}$.

Khả năng cung cấp $\mathrm{N}$ từ đất INS (indigenous nitrogen supply) được định nghĩa là tổng lượng đạm cây hấp thu được ở lô không bón đạm $(0 \mathrm{~N})$, nhưng bón đầy đủ lân, kali và các chất khác nếu đất thiếu các dưỡng chất này. INS = tổng lượng đạm hấp thu từ thân lá của lô $\mathrm{PK}$. Tương tự, khả năng cung cấp $\mathrm{P}$ từ đất IPS (indigenous phosphorus supply) là tổng lượng lân cây hấp thu được ở lô không bón lân (0P), nhưng bón đầy đủ NK. IPS = tổng lượng lân hấp thu từ thân lá, vỏ và hạt của lô $\mathrm{NK}$. Khả năng cung cấp $\mathrm{K}$ từ đất IKS (indigenous potassium supply) là tổng lượng kali cây hấp thu được ở lô không bón lân $(0 \mathrm{~K})$, nhưng bón đầy đủ NP. IKS = tổng lượng kali hấp thu từ thân lá vỏ và hạt của lô NP.

Hiệu quả nông học của phân $\mathrm{N}(\mathrm{AEN})=\left(\mathrm{GY}_{+\mathrm{N}}\right.$ $\left.-G_{0 N}\right) / F N$ Trong đó: $G_{+N}$ : năng suất ở lô bón $\mathrm{N} ; \mathrm{G}_{0 \mathrm{~N}}$ : năng suất ở lô $0 \mathrm{~N} ; \mathrm{FN}$ lượng phân $\mathrm{N}$ bón vào. Hiệu quả nông học của $\mathrm{P}$ và $\mathrm{K}$ được tính tương tự. Đáp ứng năng suất của $\mathrm{N}=$ năng suất của lô $\mathrm{NPK}$ - năng suất của lô $\mathrm{PK}$; Đáp ứng năng suất của $\mathrm{P}_{2} \mathrm{O}_{5}$ = năng suất của lô NPK - năng suất của lô NK. Đáp ứng năng suất của $\mathrm{K}_{2} \mathrm{O}=$ năng suất của lô $\mathrm{NPK}$ năng suất của lô NP.

\subsection{Xử lý số liệu}

Sử dụng phần mềm SPSS 16.0 phân tích phương sai, so sánh khác biệt trung bình giữa các nghiệm thức bằng kiểm định Duncan.

\section{KẾT QUẢ VÀ THẢO LUẬN}

\section{1. Ảnh hưởng của bón khuyết dưỡng chất $\mathbf{N}, \mathbf{P}, \mathrm{K}$ đến sinh trưởng cây mè đen}

Chiều cao cây: Nghiệm thức bón đầy đủ NPK có chiều cao cây mè cao khác biệt ý nghĩa thống kê 5\% so với nghiệm thức bón khuyết riêng lẻ dưỡng chất đạm, lân hoặc kali. Cụ thể, ở nghiệm thức bón đầy đủ NPK có chiều cao cây đạt cao nhất $(133,5 \mathrm{~cm})$, nghiệm thức bón khuyết lân và khuyết kali có chiều cao cây đạt thấp hơn, lần lượt là 106,4 và $110,7 \mathrm{~cm}$. Đối với nghiệm thức bón khuyết đạm có chiều cao cây đạt thấp nhất $81,0 \mathrm{~cm}$ so với nghiệm thức bón đầy đủ hay bón khuyết từng dưỡng chất $\mathrm{N}, \mathrm{P}$ hoặc K (Bảng 3). Kết quả tương tự được ghi nhận trên cây mè tại Nigeria, nghiệm thức không bón lân cho chiều cao cây thấp hơn so với nghiệm thức bón lân ở mức 22,5 và $45 \mathrm{~kg} \mathrm{ha}^{-1}$ (Shehu \& Sandabe, 2010).

Chiều cao đóng trái đầu tiên: Bảng 3 cho thấy nghiệm thức bón khuyết dưỡng chất đạm có chiều cao đóng trái đầu tiên đạt $50,7 \mathrm{~cm}$. Nghiệm thức bón đầy đủ NPK có chiều cao đóng trái đầu tiên là 73,0 $\mathrm{cm}$. Đối với nghiệm thức bón $\mathrm{NP}$ và $\mathrm{NK}$ có chiều dài đóng trái đầu tiên là $58,8-66,6 \mathrm{~cm}$. Bón khuyết đạm giúp cây ra hoa sớm hơn so với có bón bổ sung đạm và bón đạm ở mức cao dẫn đến cây chậm ra hoa hơn (Haruna, 2011) từ đó ảnh hưởng đến chiều cao đóng trái đầu tiên của cây mè khi không bón đạm cho chiều cao đóng trái đầu tiên thấp hơn so với bón đầy đủ đạm (Bảng 3 ). 
Đuờng kính cây: Bảng 3 cho thấy đường kính cây ở nghiệm thức bón đầy đủ NPK đạt cao nhất $(0,87 \mathrm{~cm})$ so với các nghiệm thức bón khuyết các dưỡng chất $\mathrm{N}$, $\mathrm{P}$ hoặc $\mathrm{K}$. Kế đến là nghiệm thức bón khuyết lân và khuyết kali, có đường kính cây 0,63 $0,69 \mathrm{~cm}$ và thấp nhất là nghiệm thức bón khuyết đạm $(0,50 \mathrm{~cm})$.

Bảng 3. Ảnh hưởng của bón khuyết dưỡng chất $\mathrm{N}, \mathrm{P}, \mathrm{K}$ đến sinh trưởng mè trồng tại Trại Nghiên cứu và thực nghiệm Nông nghiệp, Trường Đại học Cần Tho, tháng $10 / 2019$

\begin{tabular}{lrrrrr}
\hline $\begin{array}{l}\text { Nghiệm } \\
\text { thức }\end{array}$ & $\begin{array}{r}\text { Chiều cao cây } \\
(\mathbf{c m})\end{array}$ & $\begin{array}{r}\text { Chiều cao đóng trái đầu } \\
\text { tiên } \mathbf{( c m )}\end{array}$ & $\begin{array}{r}\text { Đường kính cây } \\
(\mathbf{c m})\end{array}$ & $\begin{array}{r}\text { Chiều dài lá } \\
(\mathbf{c m})\end{array}$ & $\begin{array}{r}\text { Chiều rộng lá } \\
(\mathbf{c m})\end{array}$ \\
\hline $\mathrm{NPK}$ & $133,5^{\mathrm{a}}$ & $73,0^{\mathrm{a}}$ & $0,87^{\mathrm{a}}$ & $14,0^{\mathrm{a}}$ & $8,75^{\mathrm{a}}$ \\
$\mathrm{NP}$ & $110,7^{\mathrm{b}}$ & $66,6^{\mathrm{ab}}$ & $0,69^{\mathrm{b}}$ & $13,0^{\mathrm{a}}$ & $7,65^{\mathrm{ab}}$ \\
$\mathrm{NK}$ & $106,4^{\mathrm{b}}$ & $58,8^{\mathrm{bc}}$ & $0,63^{\mathrm{b}}$ & $12,9^{\mathrm{a}}$ & $7,30^{\mathrm{b}}$ \\
$\mathrm{PK}$ & $81,0^{\mathrm{c}}$ & $50,7^{\mathrm{c}}$ & $0,50^{\mathrm{c}}$ & $9,5^{\mathrm{b}}$ & $3,79^{\mathrm{c}}$ \\
\hline $\mathrm{F}$ & $*$ & $*$ & $*$ & $*$ & $*$ \\
$\mathrm{CV} \%$ & 7,62 & 9,00 & 7,86 & 8,59 & 12,0 \\
\hline
\end{tabular}

Ghi chú: Trong cùng một cột số có chũ theo sau giống nhau khác biệt không có ý nghĩa thống kê, ns; khác biệt ý nghĩa thống kê 5\%(*).

Chiều dài lá: Nghiệm thức bón khuyết đạm có chiều dài lá đạt thấp nhất $9,5 \mathrm{~cm}$. Tuy nhiên, nghiệm thức bón khuyến dưỡng chất lân và kali vẫn duy trì chiều dài lá so với nghiệm thức bón đầy đủ NPK, dao động 12,9-13,0 $\mathrm{cm}$ so với $14,0 \mathrm{~cm}$, theo cùng thứ tự (Bảng 3).

Chiều rộng lá: Chiều rộng lá ở các nghiệm thức khác biệt có ý nghĩa thống kê $5 \%$. Chiều rộng lá ở các nghiệm thức bón $\mathrm{NPK}, \mathrm{NP}, \mathrm{NK}$ và $\mathrm{PK}$ lần lượt là $8,75,7,65,7,30$ và $3,79 \mathrm{~cm}$ (Bảng 3 ). Đạm là thành phần của chlorophyll (Lawlor, 2002). Do đó, thiếu đạm làm giảm khả năng quang hợp và giảm diện tích lá (Cechin \& Fumis, 2004).

3.2. Ảnh hưởng của bón khuyết dưỡng chất $\mathrm{N}, \mathrm{P}, \mathrm{K}$ đến thành phần năng suất và năng suất hạt mè đen

Tổng số trái/cây: Nghiệm thức bón khuyết dưỡng chất $\mathrm{N}$ có tổng số trái trên cây đạt thấp nhất (13,1 trái). Kế đến là nghiệm thức bón khuyết lân và kali, với 23,5 - 24,3 trái/cây. Tổng số trái đạt cao nhất ở nghiệm thức bón đầy đủ NPK, với 53,4 trái/cây (Bảng 4).

Chiều dài trái: Chiều dài trái giữa các nghiệm thức khác biệt có ý nghĩa thống kê 5\%. Trong đó, nghiệm thức bón đầy đủ NPK đạt $2,94 \mathrm{~cm}$ cao hơn các nghiệm thức $\mathrm{NP}, \mathrm{NK}$ và $\mathrm{PK}$, với 2,27-2,45 cm (Bảng 4).

Đuờng kính trái: Bảng 4 cho thấy đường kính trái ở nghiệm thức bón đầy đủ NPK cao khác biệt có ý nghĩa thống kê $5 \%$ so với nghiệm thức bón khuyết riêng lẻ từng dưỡng chất $\mathrm{N}, \mathrm{P}$ hoặc $\mathrm{K}$. Chiều dài trái và đường kính trái ở nghiệm thức bón $\mathrm{NPK}, \mathrm{NP}, \mathrm{NK}$ và $\mathrm{PK}$ lần lượt là $1,28>1,11>1,05 \sim 1,02 \mathrm{~cm}$.

Khối lương 1.000 hạt: Kết quả Bảng 4 cho thấy khối lượng 1.000 hạt của các nghiệm thức bón khuyết các dưỡng chất $\mathrm{N}, \mathrm{P}, \mathrm{K}$ khác biệt không có ý nghĩa thống kê, với khối lượng trung bình 2,33 g.

Bảng 4. Ảnh hưởng của bón khuyết dưỡng chất $\mathrm{N}, \mathrm{P}, \mathrm{K}$ đến thành phần năng suất và năng suất mè trồng tại Trại Nghiên cứu và thực nghiệm Nông nghiệp, Trường Đại học Cần Thơ, tháng 10/2019

\begin{tabular}{|c|c|c|c|c|c|}
\hline Nghiệm thức & $\begin{array}{r}\text { Tổng số } \\
\text { trái/cây (trái) }\end{array}$ & $\begin{array}{r}\text { Chiều dài trái } \\
(\mathbf{c m})\end{array}$ & $\begin{array}{r}\text { Đường kính } \\
\text { trái }(\mathrm{cm})\end{array}$ & $\begin{array}{r}\text { Khối lượng } 1000 \\
\text { hạt (g) }\end{array}$ & $\begin{array}{r}\text { Năng suất } \\
\left(\mathrm{g} / \mathbf{m}^{2}\right)\end{array}$ \\
\hline NPK & $53,4^{\mathrm{a}}$ & $2,94^{\mathrm{a}}$ & $1,28^{\mathrm{a}}$ & 2,40 & $103,2^{\mathrm{a}}$ \\
\hline NP & $24,3^{\mathrm{b}}$ & $2,40^{\mathrm{b}}$ & $1,11^{\mathrm{b}}$ & 2,36 & $101,9^{\mathrm{a}}$ \\
\hline NK & $23,5^{\mathrm{b}}$ & $2,45^{\mathrm{b}}$ & $1,05^{\mathrm{c}}$ & 2,23 & $99,3^{\mathrm{a}}$ \\
\hline PK & $13,1^{\mathrm{c}}$ & $2,27^{\mathrm{b}}$ & $1,02^{\mathrm{c}}$ & 2,33 & $68,8^{c}$ \\
\hline $\bar{F}$ & $*$ & $*$ & $*$ & ns & * \\
\hline $\mathrm{CV}(\%)$ & 11,5 & 5,97 & 3,01 & 5,42 & 7,98 \\
\hline
\end{tabular}

Ghi chú: Trong cùng một cột số có chũ theo sau giống nhau khác biệt không có ý nghĩa thống kê, ns; khác biệt ý nghĩa thống kê 5\%(*). 
Năng suất hạt mè: Bảng 4 cho thấy nghiệm thức bón khuyết dưỡng chất đạm dẫn đến giảm năng suất hạt, với $68,8 \mathrm{~g} \mathrm{~m}^{-2}$. Tuy nhiên, nghiệm thức bón khuyết lân và kali vẫn duy trì năng suất mè so với nghiệm thức bón đầy đủ dưỡng chất NPK, với năng suất lần lượt là $99,3-101,9 \mathrm{~g} \mathrm{~m}^{-2}$ so với 103,2 $\mathrm{g} \mathrm{m}^{-2}$.

(a)

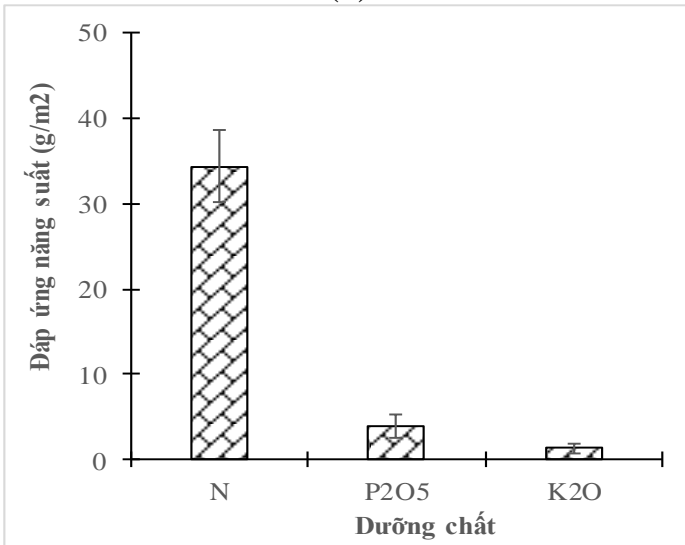

3.3. Ảnh hưởng của bón khuyết dưỡng chất $N, P, K$ đến hiệu quả nông học của phân NPK trên đất phù sa không được bồi trồng mè đen

Đáp ứng năng suất mè của phân $\mathrm{N}, \mathrm{P}_{2} \mathrm{O}_{5}$ và $\mathrm{K}_{2} \mathrm{O}$ được xác định là $34,38,3,93$ và $1,35 \mathrm{~g} \mathrm{~m}^{-2}$ (Hình $1 \mathrm{a}$ ). Kết quả cũng cho thấy bón $1 \mathrm{~g}$ đạm tăng $3,82 \mathrm{~g}$ mè. Tương tự, bón $1 \mathrm{~g} \mathrm{P}_{2} \mathrm{O}_{5}$ và $\mathrm{K}_{2} \mathrm{O}$ tăng 0,66 và $0,45 \mathrm{~g}$ mè, theo cùng thứ tự (Hình $1 \mathrm{~b}$ ).

(b)

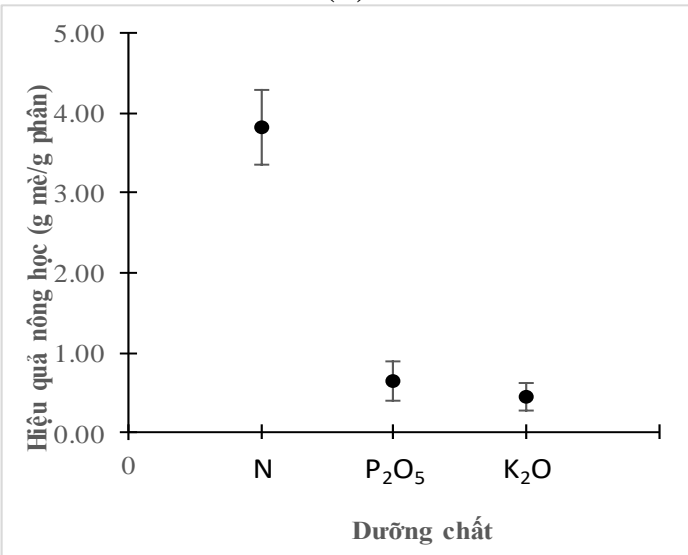

Hình 1. Ảnh hưởng của bón khuyết dưỡng chất $\mathrm{N}, \mathrm{P}, \mathrm{K}$ đến (a) đáp ứng năng suất mè và (b) hiệu quả nông học của phân NPK tại Trại Nghiên cứu và thực nghiệm Nông nghiệp, Trường Đại học Cần Tho, tháng 10/2019

\section{4. Ảnh hưởng của bón khuyết dưỡng chất $\mathbf{N}, \mathbf{P}, \mathrm{K}$ đển đặc tính đất phù sa không được bồi trồng mè đen}

Các nghiệm thức bón đầy đủ hay bón riêng lẻ từng dưỡng chất $\mathrm{N}, \mathrm{P}$ hoặc $\mathrm{K}$ có giá trị $\mathrm{pH}_{\mathrm{H} 2 \mathrm{O}}$ khác biệt không có ý nghĩa thống kê, với giá trị trung bình 6,44 . Tuy nhiên, hàm lượng đạm hữu dụng ở các nghiệm thức có bón đạm đạt $2,53 \mathrm{mg} \mathrm{NH}_{4}{ }^{+} \mathrm{kg}^{-1}$ cao khác biệt có ý nghĩa thống kê $5 \%$ so với nghiệm thức khuyết đạm, với $1,46 \mathrm{mg} \mathrm{NH}_{4}{ }^{+} \mathrm{kg}^{-1}$. Tương tự, hàm lượng lân dễ tiêu ở nghiệm thức bón khuyết lân đạt
73,4 mg P kg${ }^{-1}$, thấp khác biệt có ý nghĩa thống kê $5 \%$ so với nghiệm thức có bón lân, dao động 157,4$172,1 \mathrm{mg} \mathrm{P} \mathrm{kg}^{-1}$. Hàm lượng kali trao đổi ở nghiệm thức NPK là 0,63 meq K ${ }^{+} 100 \mathrm{~g}^{-1}$, giá trị này đạt thấp hơn ở nghiệm thức $\mathrm{NP}$, với 0,25 meq $\mathrm{K}^{+} 100 \mathrm{~g}^{-1}$ (Bảng 5). Bón đạm giúp cây trồng sinh trưởng tốt, nhưng làm giảm lượng lân dễ tiêu và kali trao đổi trong đất do cây trồng hấp thu để cân bằng với lượng đạm có trong cây (Brady, 2008). Bên cạnh đó, trong thí nghiệm có các nghiệm thức không bón bổ sung lân và kali nên đã làm giảm hàm lượng lân dễ tiêu và kali trao đổi trong đất.

Bảng 5. Ảnh hưởng của bón khuyết dưỡng chất $\mathrm{N}, \mathrm{P}, \mathrm{K}$ đến đặc tính đất phù sa không được bồi trồng mè đen tại Trại Nghiên cứu và thực nghiệm Nông nghiệp, Trường Đại học Cần Thơ, tháng 10/2019

\begin{tabular}{|c|c|c|c|c|}
\hline \multirow{2}{*}{ Nghiệm thức } & & $\frac{\text { Đạm hữu dụng }}{\left(\mathrm{mg} \mathrm{kg}^{-1}\right)}$ & Lân dễ tiêu & \multirow{2}{*}{$\frac{\text { Kali trao đổi }}{\left(\text { meq } 100 \mathrm{~g}^{-1}\right)}$} \\
\hline & & \multicolumn{2}{|l|}{$\left(\mathrm{mg} \mathrm{kg}^{-1}\right)$} & \\
\hline \multirow{4}{*}{$\begin{array}{l}\text { NPK } \\
\text { NP } \\
\text { NK } \\
\text { PK }\end{array}$} & $\frac{\mathbf{p H}_{\mathbf{H} 2 \mathrm{O}}}{6,50}$ & $2,53^{\mathrm{a}}$ & (172 1a & \multirow{2}{*}{$\begin{array}{l}0,63^{\mathrm{a}} \\
0,25^{\mathrm{b}}\end{array}$} \\
\hline & 6,45 & $2,99^{\mathrm{a}}$ & \multirow{3}{*}{$\begin{array}{r}163,9^{\mathrm{ab}} \\
73,4^{\mathrm{c}} \\
157,4^{\mathrm{a}}\end{array}$} & \\
\hline & 6,34 & $2,62^{\mathrm{a}}$ & & $0,42^{\mathrm{ab}}$ \\
\hline & 6,45 & $1,46^{\mathrm{b}}$ & & $0,35^{\mathrm{b}}$ \\
\hline $\mathrm{F}$ & ns & $*$ & $*$ & \multirow{2}{*}{$\begin{array}{r}* \\
7,81\end{array}$} \\
\hline $\mathrm{CV}(\%)$ & 2,26 & 14,0 & 5,82 & \\
\hline
\end{tabular}

Ghi chú: Trong cùng một cột số có chũ theo sau giống nhau khác biệt không có ý nghĩa thống kê, ns; khác biệt ý nghĩa thống kê 5\% (*). 


\section{5. Ảnh hưởng của bón khuyết dưỡng chất $\mathrm{N}, \mathrm{P}, \mathrm{K}$ đến hấp thu NPK của cây mè trồng trên đất phù sa không được bồi}

Hàm luợng đạm: Bảng 6 cho thấy hàm lượng đạm trong thân lá, vỏ và hạt giữa các nghiệm thức khác biệt ý nghĩa thống kê $5 \%$. Hàm lượng đạm trong thân lá và vỏ mè dao động từ 0,54 đến $0,98 \%$. Các nghiệm thức có bón đạm có hàm lượng đạm trong hạt 3,48-3,52\% trong khi nghiệm thức không bón đạm chỉ đạt $3,29 \%$.

Hàm lương lân: Nghiệm thức bón khuyết $\mathrm{P}$ có hàm lượng lân thân lá và vỏ $(0,32$ và $0,44 \%$ theo thứ tự). Trong đó, hàm lượng lân trong thân lá thấp hơn so với nghiệm thức bón đầy đủ NPK. Mặc khác, hàm lượng lân trong hạt khác biệt không có ý nghĩa thống kê giữa các nghiệm thức, với giá trị trung bình $0,71 \%$ (Bảng 6).

Hàm lượng kali: Không bổ sung $\mathrm{K}$ chưa dẫn đến sự khác biệt có ý nghĩa thống kê về hàm lượng $\mathrm{K}$ trong thân, lá. Tuy nhiên, hàm lượng $\mathrm{K}$ trong vỏ hạt ở nghiệm thức NPK cao hơn nghiệm thức khuyết $\mathrm{K}$, với hàm lượng 1,08 và $0,90 \%$ trong vỏ và 3,96 và 2,16\% trong hạt, theo thứ tự (Bảng 6).

Sinh khối: Giữa các nghiệm thức bón khuyết các dưỡng chất $\mathrm{N}, \mathrm{P}$ và $\mathrm{K}$ cho sinh khối thân lá và hạt khác biệt có ý nghĩa thống kê $5 \%$. Cụ thể, nghiệm thức bón khuyết đạm có sinh khối thân lá đạt $87,3 \mathrm{~g}$ $\mathrm{m}^{-2}$, kế tiếp là nghiệm thức khuyết $\mathrm{P}$ và $\mathrm{K}(169,4$ và $170,8 \mathrm{~g} \mathrm{~m}^{-2}$ ), thẩp hơn so với nghiệm thức bón đầy đủ NPK $179,1 \mathrm{~g} \mathrm{~m}^{-2}$. Đối với sinh khối vỏ của nghiệm thức $\mathrm{NPK}, \mathrm{NP}, \mathrm{NK}$ và $\mathrm{PK}$ lần lượt là 54,1 , $52,9,51,5$ và $49,3 \mathrm{~g} \mathrm{~m}^{-2}$. Tương tự, sinh khối hạt ở nghiệm thức bón khuyết đạm $\left(46,8 \mathrm{~g} \mathrm{~m}^{-2}\right)$ thấp hơn so với các nghiệm thức có bón đạm (71,7-73,2 $\mathrm{g} \mathrm{m}^{-}$ 2) (Bảng 6).

Hấp thu đạm trong các bộ phận cây mè: Hấp thu đạm trong thân, lá, vỏ và hạt của các nghiệm thức có bón đạm cao khác biệt ý nghĩa thống kê 5\% so với nghiệm thức không bón đạm. Trong đó, hấp thu đạm trong thân lá đạt 1,03-1,34 $\mathrm{g} \mathrm{m}^{-2}$ đối với nghiệm thức $\mathrm{NPK}, \mathrm{NP}$ và $\mathrm{NK}$ trong khi ở nghiệm thức $\mathrm{PK}$ đạt $0,47 \mathrm{~g} \mathrm{~m}^{-2}$. Tương tự, hàm lượng $\mathrm{N}$ trong vỏ theo trật tự 0,53 0,51>0,38>0,30 $\mathrm{g} \mathrm{m}^{-2}$ đối với nghiệm thức NPK, NP, NK và $\mathrm{PK}$. Đối với hấp thu đạm trong hạt ghi nhận 2,50-2,56 $\mathrm{g} \mathrm{m}^{-2}$ ở nghiệm thức $\mathrm{NPK}, \mathrm{NP}$ và $\mathrm{NK}$ so với giá trị $1,54 \mathrm{~g} \mathrm{~m}^{-2}$ ở nghiệm thức PK (Bảng 7).

Hấp thu lân trong các bộ phân cây mè: Nghiệm thức bón đầy đủ dưỡng chất NPK có hấp thu lân trong thân lá và hạt khác biệt có ý nghĩa thống kê $5 \%$. Cụ thể, nghiệm thức bón đầy đủ NPK cho sinh khối thân lá đạt cao nhất $\left(1,26 \mathrm{~g} \mathrm{~m}^{-2}\right)$ so với nghiệm thức bón khuyết các dưỡng chất $\mathrm{N}, \mathrm{P}$ hoặc $\mathrm{K}$, dao động $0,49-0,90 \mathrm{~g} \mathrm{~m}^{-2}$. Hấp thu lân trong vỏ giữa các nghiệm thức khác biệt không có ý nghĩa thống kê, trung bình $0,27 \mathrm{~g} \mathrm{~m}^{-2}$. Hấp thu lân trong hạt ở nghiệm thức không bón $\mathrm{P}$ khác biệt không có ý nghĩa thống kê so với nghiệm thức bón đầy đủ NPK, nhưng ở nghiệm thức bón PK cho hấp thu lân trong hạt đạt thấp nhất $\left(0,34 \mathrm{~g} \mathrm{~m}^{-2}\right)$, khác biệt có ý nghĩa thống kê $5 \%$ so với nghiệm thức bón NPK $(0,51 \mathrm{~g}$ $\mathrm{m}^{-2}$ ) (Bảng 7).

Hấp thu kali trong các bộ phận cây mè: Hấp thu kali giữa các nghiệm thức khác biệt có ý nghĩa thống kê $5 \%$. Trong đó, hấp thu kali trong thân, lá ở nghiệm thức dao động 1,14-2,40 $\mathrm{g} \mathrm{m}^{-2}$. Hấp thu kali trong vỏ cuả nghiệm thức NP thấp hơn nghiệm thức $\mathrm{NPK}$, với lượng hấp thu 0,48 và $0,59 \mathrm{~g} \mathrm{~m}^{-2}$, theo thứ tự. Đối với hấp thu kali trong hạt, nghiệm thức NPK đạt giá trị $2,90 \mathrm{~g} \mathrm{~m}^{-2}$ trong khi các nghiệm thức còn lại 1,26-2,02 $\mathrm{g} \mathrm{m}^{-2}$ (Bảng 7).

Tổng hấp thu $N, P, K$ : Tổng hấp thu đạm của các nghiệm thức có bón đạm cao khác biệt có ý nghĩa thống kê $5 \%$ so với nghiệm thức không bón đạm, với 3,94-4,43 $\mathrm{g} \mathrm{m}^{-2}$ đối với nghiệm thức NPK, NP và $\mathrm{NK}$ và $2,31 \mathrm{~g} \mathrm{~m}^{-2}$ ở nghiệm thức $\mathrm{PK}$. Tương tự, tổng hấp thu lân ở nghiệm thức NK thấp hơn so với nghiệm thức bón đầy đủ NPK, với 1,28 và $2,05 \mathrm{~g} \mathrm{~m}^{-}$ ${ }^{2}$, theo thứ tự. Tổng hấp thu kali giữa các nghiệm thức khác biệt có ý nghĩa thống kê 5\%. Trong đó, nghiệm thức NPK và $\mathrm{NK}$ đạt 4,99-5,75 $\mathrm{g} \mathrm{m}^{-2}$, cao hơn nghiệm thức $\mathrm{NP}$ và $\mathrm{PK}$, với $2,88-3,96 \mathrm{~g} \mathrm{~m}^{-2}$ (Bảng 7). Nghĩa là dưỡng chất $\mathrm{N}, \mathrm{P}, \mathrm{K}$ đất cung cấp là $2,31,1,28$ và $3,96 \mathrm{~g} \mathrm{~m}^{-2}$. 
Bảng 6. Ảnh hưởng của bón khuyết dưỡng chất $\mathrm{N}, \mathrm{P}, \mathrm{K}$ đến hàm lượng NPK của cây mè đen trồng tại Trại Nghiên cứu và thực nghiệm Nông nghiệp, Trường Đại học Cần Thơ, tháng 10/2019

\begin{tabular}{|c|c|c|c|c|c|c|c|c|c|c|c|c|}
\hline \multirow[b]{2}{*}{$\begin{array}{l}\text { Nghiệm } \\
\text { thức }\end{array}$} & \multicolumn{3}{|c|}{ Hàm lượng đạm } & \multicolumn{3}{|c|}{ Hàm lượng lân } & \multicolumn{3}{|c|}{ Hàm lượng kali } & \multicolumn{3}{|c|}{ Sinh khối khô } \\
\hline & $\begin{array}{r}\text { Thân, } \\
\text { lá }\end{array}$ & Vỏ & Hạt & $\begin{array}{r}\text { Thân, } \\
\text { lá }\end{array}$ & Vỏ & Hạt & $\begin{array}{r}\text { Thân, } \\
\text { lá }\end{array}$ & Vỏ & Hạt & $\begin{array}{r}\text { Thân, } \\
\text { lá }\end{array}$ & Vỏ & Hạt \\
\hline & \multicolumn{9}{|c|}{$(\%)$} & \multicolumn{3}{|c|}{$\left(\mathrm{g} \mathrm{m}^{-2}\right)$} \\
\hline NPK & $0,75^{\mathrm{a}}$ & $0,98^{\mathrm{a}}$ & $3,50^{\mathrm{a}}$ & $0,71^{\mathrm{a}}$ & $0,50^{\mathrm{ab}}$ & 0,70 & 1,26 & $1,08^{\mathrm{a}}$ & $3,96^{\mathrm{a}}$ & $179,1^{\mathrm{a}}$ & $54,1^{\mathrm{a}}$ & $73,2^{\mathrm{a}}$ \\
\hline NP & $0,63^{\mathrm{b}}$ & $0,96^{\mathrm{a}}$ & $3,48^{\mathrm{a}}$ & $0,53^{\mathrm{b}}$ & $0,54^{\mathrm{ab}}$ & 0,70 & 1,13 & $0,90^{\mathrm{b}}$ & $2,16^{\mathrm{b}}$ & $170,8^{b}$ & $52,9^{\mathrm{ab}}$ & $71,9^{\mathrm{a}}$ \\
\hline NK & $0,61^{\mathrm{b}}$ & $0,75^{\mathrm{b}}$ & $3,52^{\mathrm{a}}$ & $0,32^{c}$ & $0,44^{\mathrm{b}}$ & 0,71 & 1,42 & $1,08^{\mathrm{a}}$ & $2,84^{\mathrm{ab}}$ & $169,4^{\mathrm{b}}$ & $51,5^{\mathrm{bc}}$ & $71,7^{\mathrm{a}}$ \\
\hline PK & $0,54^{\mathrm{c}}$ & $0,61^{\mathrm{c}}$ & $3,29^{\mathrm{b}}$ & $0,56^{\mathrm{b}}$ & $0,61^{\mathrm{a}}$ & 0,73 & 1,30 & $0,97^{\mathrm{ab}}$ & $2,70^{\mathrm{b}}$ & $87,3^{\mathrm{c}}$ & $49,3^{\mathrm{c}}$ & $46,8^{\mathrm{b}}$ \\
\hline $\bar{F}$ & * & $*$ & * & * & $*$ & $\mathrm{~ns}$ & ns & $*$ & * & * & $*$ & * \\
\hline $\mathrm{CV}(\%)$ & 4,03 & 7,12 & 1,34 & 10,8 & 13,9 & 2,66 & 11,4 & 8,33 & 25,5 & 3,42 & 2,98 & 1,72 \\
\hline
\end{tabular}

Ghi chú: Trong cùng một cột số có chũ theo sau giống nhau khác biệt không có ý nghĩa thống kê, ns; khác biệt ý nghĩa thống kê $5 \%$ (*).

Bảng 7. Ảnh hưởng của bón khuyết dưỡng chất N, P, K đến hấp thu NPK của cây mè đen trồng tại Trại Nghiên cứu và thực nghiệm Nông nghiệp, Trường Đại học Cần Thơ, tháng 10/2019

\begin{tabular}{|c|c|c|c|c|c|c|c|c|c|c|c|c|}
\hline \multirow{3}{*}{$\begin{array}{l}\text { Nghiệm } \\
\text { thức }\end{array}$} & \multicolumn{3}{|c|}{ Hấp thu đạm } & \multicolumn{3}{|c|}{ Hấp thu lân } & \multicolumn{3}{|c|}{ Hấp thu kali } & \multicolumn{3}{|c|}{ Tổng hấp thu } \\
\hline & $\begin{array}{r}\text { Thân, } \\
\text { lá }\end{array}$ & Vỏ & Hạt & $\begin{array}{r}\text { Thân, } \\
\text { lá }\end{array}$ & Vỏ & Hạt & $\begin{array}{r}\text { Thân, } \\
\text { lá }\end{array}$ & Vỏ & Hạt & Đạm & Lân & Kali \\
\hline & \multicolumn{12}{|c|}{$\left(\mathrm{g} \mathrm{m}^{-2}\right)$} \\
\hline NPK & $1,34^{\mathrm{a}}$ & $0,53^{\mathrm{a}}$ & $2,56^{\mathrm{a}}$ & $1,26^{\mathrm{a}}$ & 0,27 & $0,51^{\mathrm{a}}$ & $2,27^{\mathrm{ab}}$ & $0,59^{\mathrm{a}}$ & $2,90^{\mathrm{a}}$ & $4,43^{\mathrm{a}}$ & $2,05^{\mathrm{a}}$ & $5,75^{\mathrm{a}}$ \\
\hline NP & $1,08^{\mathrm{b}}$ & $0,51^{\mathrm{a}}$ & $2,50^{\mathrm{a}}$ & $0,90^{\mathrm{b}}$ & 0,28 & $0,50^{\mathrm{a}}$ & $1,93^{b}$ & $0,48^{\mathrm{b}}$ & $1,55^{\mathrm{b}}$ & $4,08^{b}$ & $1,69^{b}$ & $3,96^{\mathrm{b}}$ \\
\hline NK & $1,03^{\mathrm{b}}$ & $0,38^{\mathrm{b}}$ & $2,53^{\mathrm{a}}$ & $0,55^{\mathrm{c}}$ & 0,22 & $0,51^{\mathrm{a}}$ & $2,40^{\mathrm{a}}$ & $0,56^{\mathrm{ab}}$ & $2,02^{\mathrm{b}}$ & $3,94^{\mathrm{c}}$ & $1,28^{c}$ & $4,99^{\mathrm{a}}$ \\
\hline PK & $0,47^{\mathrm{c}}$ & $0,30^{\mathrm{c}}$ & $1,54^{\mathrm{b}}$ & $0,49^{c}$ & 0,30 & $0,34^{\mathrm{b}}$ & $1,14^{\mathrm{c}}$ & $0,48^{\mathrm{b}}$ & $1,26^{\mathrm{b}}$ & $2,31^{\mathrm{d}}$ & $1,13^{\mathrm{c}}$ & $2,88^{\mathrm{c}}$ \\
\hline $\mathrm{F}$ & $*$ & * & $*$ & * & $\mathrm{ns}$ & * & $*$ & $*$ & $*$ & $*$ & * & * \\
\hline CV $(\%)$ & 4,37 & 5,90 & 1,78 & 12,3 & 12,8 & 3,80 & 14,2 & 10,5 & 26,6 & 1,72 & 7,53 & 12,1 \\
\hline
\end{tabular}

Ghi chú: Trong cùng một cột số có chũ theo sau giống nhau khác biệt không có ý nghĩa thống kê, ns; khác biệt ý nghĩa thống kê $5 \%(*)$.

\section{KẾT LUẬN VÀ ĐỀ NGH!}

\subsection{Kết luận}

Đáp ứng năng suất của bón $\mathrm{N}, \mathrm{P}_{2} \mathrm{O}_{5}$ và $\mathrm{K}_{2} \mathrm{O}$ được xác định là $34,38,3,93$ và $1,35 \mathrm{~g} \mathrm{~m}^{-2}$.

Bón đạm giúp tăng chiều cao cây, đường kính cây, chiều dài, đường kính trái mè, thành phần năng suất cây mè đen như số trái trên cây và năng suất mè. Tuy nhiên, bón lân và kali chưa dẫn đến sự khác biệt về năng suất mè.

Lượng dưỡng chất N-P-K hấp thu ở cây mè là $4,43,2,05$ và $5,75 \mathrm{~g} \mathrm{~m}^{-2}$ trong khi lượng dưỡng chất $\mathrm{N}, \mathrm{P}, \mathrm{K}$ đất có thể cung cấp là $2,31,1,28$ và $3,96 \mathrm{~g}$ $\mathrm{m}^{-2}$.

\section{2. Đề nghị}

Ứng dụng phương pháp bón khuyết dưỡng chất để xây dựng công thức phân NPK nhằm bón phân cân đối cho cây mè đen ở điều kiện đồng ruộng.

\section{LÒ̀I CẢM TẠ}

Đề tài này được tài trợ bởi Dự án Nâng cấp Trường Đại học Cần Thơ VN14-P6 bằng nguồn vốn vay ODA từ Chính phủ Nhật Bản.

\section{TÀI LIỆU THAM KHẢO}

Ali, M. A., Abbas, G., Mohy-ud-Din, Q., Ullah, K., Abbas, G. \& Aslam, M. (2010). Response of mungbean (Vigna radiata) to phosphatic fertilizer under arid climate. The Journal of Animal \& Plant Sciences, 20(2), 83-86.

Amare, M., Fisseha, D., \& Andreasen, C. (2019). The Effect of $\mathrm{N}$ and $\mathrm{P}$ fertilizers on yield and yield components of Sesame (Sesamum indicum L.) in low-fertile soil of NorthWestern Ethiopia. Agriculture, 9(10), 227. https://doi.org/10.3390/agriculture9100227

Bijarnia, A., Sharma, O. P., Kumar, R., Kumawat, R., \& Choudhary, R. (2019). Effect of nitrogen and potassium on growth, yield and nutrient uptake of sesame (Sesamum indicum L.) under loamy sand soil of Rajasthan. Journal of Pharmacognosy and 
Phytochemistry, 8(3), 566-570.

https://doi.org/10.20546/ijcmas.2019.806.017

Brady, N. C., Weil, R. R., \& Weil, R. R. (2008).

The nature and properties of soils. Upper

Saddle River, NJ: Prentice Hall. 10.1023/A:1016012810895

Cechin, I., \& de Fátima Fumis, T. (2004). Effect of nitrogen supply on growth and photosynthesis of sunflower plants grown in the greenhouse. Plant Science, 166(5), 13791385 .

https://doi.org/10.1016/j.plantsci.2004.01.020

Haruna, I. M. (2011). Growth and yield of sesame (Sesamum indicum L.) as influenced by nitrogen and intra row spacing in Lafia, Nasarawa State of Nigeria. Elixir Agriculture, 41(2011), 5685-5688.

Lawlor, D. W. (2002). Carbon and nitrogen assimilation in relation to yield: mechanisms are the key to understanding production systems, Journal of Experimental Botany, 53(370), 773 - 787. https://doi.org/10.1093/jxb/P53.370.773

Lominadze, S., \& Nakashidze, N. (2016). The influence of nitrogen fertilizers on nitrate accumulation in leaves of orange Washington Navel. Annals of agrarian science, 14(3), 233236. https://doi.org/10.1016/j.aasci.2016.07.008

Nguyễn Bảo Vệ, Trần Thị Kim Ba, Nguyễn Thị Xuân Thu, Lê Vĩnh Thúc, \& Bùi Thị Cẩm Hường. (2011). Giáo trình cây công nghiệp ngắn ngày. Nhà xuất bản Đại học Cần Thơ.

Nguyễn Văn Chương \& Võ Văn Quang. (2015). Mè (Sesamum indicum L.) cây trồng cần phát triển để chuyển đổi co cấu cho vùng Đồng Bằng Sông Củu Long [Báo cáo tại hội thảo]. Hội thảo khoa học - Cây vừng - Tiềm năng và định hướng phát triển vùng nguyên liệu ở Đồng Tháp Mười. Trung tâm Nghiên cứu và phát triển nông thôn Đồng Tháp Mười. http://iasvn.org/upload/files/M7YOK2EVMC Me.PDF

Shehu, H. E., Kwari, J. D., \& Sandabe, M. K. (2009). Nitrogen, Phosphorus and Potassium Nutrition of Sesame (Sesamum indicum) in Mubi, Nigeria. Research Journal of Agronomy, 3(3), 32-36.

https://medwelljournals.com/abstract/?doi=rja gr.2009.32.36

Sparks, D. L., Page, A. L., Helmke, P. A., Loeppert, R. H., Soltanpour, P. N., Tabatabai, M. A., Johnston, C. T., \& Sumner, M. E. (Eds.). (1996). Methods of soil analysis. Part 3-Chemical methods. Soil Science Society of America, Inc. https://doi.org/10.2136/sssabookser5.3

Trung tâm Tin học và Thống kê. (2019). Báo cáo kết quả thực hiện sản xuất, kinh doanh ngành nông nghiệp và phát triển nông thôn tháng 10 và 10 tháng đầu năm 2019.

https://www.mard.gov.vn/ThongKe/Lists/Bao CaoThongKe/Attachments/154/Baocao_T10_ 2019.pdf

Zenawi, G., \& Mizan, A. (2019). Effect of nitrogen fertilization on the growth and seed yield of Sesame (Sesamum indicum L.). International Journal of Agronomy, 2019, Article ID 5027254. 1-7. https://doi.org/10.1155/2019/5027254 